www.jmscr.igmpublication.org

Impact Factor (SJIF): 6.379

Index Copernicus Value: 79.54

ISSN (e)-2347-176x ISSN (p) 2455-0450

crossrefDOI: https://dx.doi.org/10.18535/jmscr/v6i12.92

\title{
Valgus subtrochanteric Osteotomy with double angle DHS fixation in late presented fracture neck of femur
}

\author{
Authors \\ Binod Chandra Raulo, Budheswar Majhi* \\ Department of Orthopaedics, IMS and SUM Hospital, Siksha O Anusandhan University, K 8, Kalinga \\ Nagar, Odisha, Bhubaneswar, India \\ *Corresponding Author \\ Dr Budheswar Majhi \\ Associate Professor, Department of Orthopaedics, IMS and Sum Hospital, Bhubaneswar, India \\ Email: budheswarmajhi@soa.ac.in
}

\section{Introduction}

Femoral neck cracks in moderately youthful patients ought to be treated by decrease and inflexible obsession to safeguard the patient's own hip ${ }^{[1-9]}$. Be that as it may, this treatment may result in non-association due to mechanical and natural variables $^{[5]}$. This can be credited to the ongoing advances in hip substitution. Intertrochanteric osteotomy changes the biomechanical condition of the crack site and upgrades break association ${ }^{[4]}$. In spite of the fact that this system is all around portrayed in the orthopedic writing ${ }^{[2,10-15]}$, numerous youthful orthopedic specialists may have little attention to this technique.

Intertrochanteric osteotomy was first presented by Pauwels ${ }^{[15]}$ in 1927. It was utilized as a technique to treat numerous hip issues ${ }^{[1,9-12]}$ and prevailing with regards to dodging or deferring hip substitution or hip reemerging in youthful patients. In vertical breaks and non-associations of the femoral neck, the osteotomy reorients the crack, changing over shear powers at the break site into compressive powers, which improves break mending ${ }^{[3,4,15]}$. Müller ${ }^{[13]}$ presented the twofold calculated $120^{\circ}$ plate for inside obsession of the osteotomy. The twofold calculated DHS enables the osteotomy to mend with medialisation and verticalisation of the femoral shaft (Fig. 1a). This disfigurement causes strain of the average tendon of the knee joint, genu valgum and at last knee osteoarthritis (Fig. 1b). It additionally makes add up to hip substitution troublesome if necessary later on. Utilizing a solitary calculated plate may stay away from this issue. The point of this report is to exhibit our involvement in treating uprooted vertical cracks and non-associations of the femoral neck by valgus intertrochanteric osteotomy and obsession by $120^{\circ}$ twofold calculated DHS.

\section{Patients and strategies}

This investigation was completed in the creators' foundation, a college showing healing facility, somewhere in the range of 2000 and 2007. It included 36 patients: 26 men and ten ladies. Their normal age was $37(18-49)$ years. Nineteen were 
as of late dislodged vertical breaks of the femoral neck, and 17 were ununited cracks after fizzled inner obsession. All patients were treated by wedge-expelling valgus intertrochanteric osteotomy. The obsession gadget was $120^{\circ}$ twofold calculated DHS plate in all patients. The investigation was affirmed by the moral board of our organization, and all patients gave educated assent. Watchful preoperative arranging was done for each situation (Fig. 2a-c). To begin with, the crack point, between the break plane and opposite to the femoral pivot, is estimated in a standard anteroposterior radiograph. Second, the osteotomy edge is estimated (Fig. 2a). This edge is equivalent to the break edge short $25^{\circ}$ which is the aftereffect of the compressive powers at the hip ${ }^{[13]}$ (Fig. 2b). Third, the seating etch addition edge is recognized, which is the point of the sharp edge plate $\left(120^{\circ}\right)$ less the osteotomy edge. On the off chance that the osteotomy point is $40^{\circ}$, the edge between the seating etch and the femoral shaft will be $90^{\circ}$. Fourth, the passage purpose of the seating etch ought to be at any rate $2.5 \mathrm{~cm}$ over the arranged upper cut of the osteotomy. Osteotomy level is at or somewhat better than the lesser trochanter level.

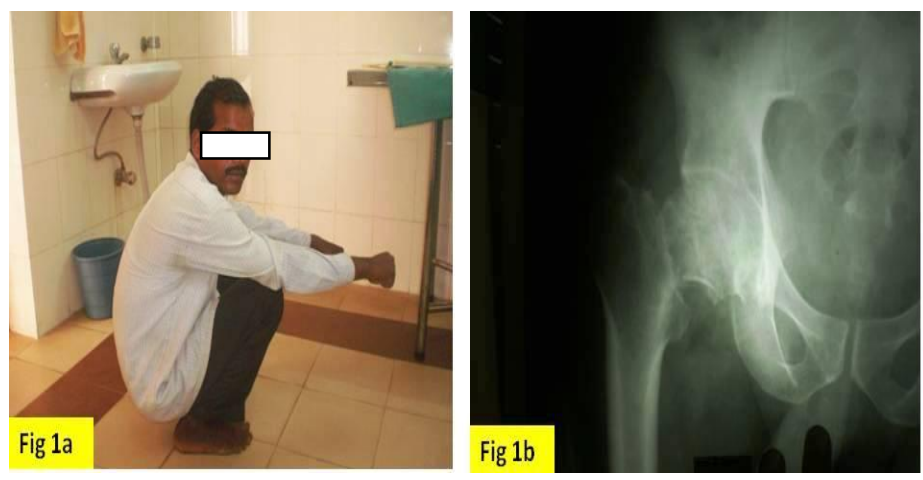

Fig 1

\section{Blade insertion}

The activity is performed on a radiolucent crack table for fluoroscopic direction. The seating etch is embedded along a guide wire going for the inferomedial quadrant of the femoral head at the pre-templated inclusion point. Its position is checked by fluoroscopy, and after that the $120^{\circ}$ twofold calculated DHS plate is presented. The side plate currently stands from the femoral shaft, making an edge equivalent to the ideal osteotomy edge (Fig. 2c). Osteotomy cuts A V-formed wedge evacuating osteotomy is performed. The upper cut of the osteotomy is transverse. Remedy of any outside pivot or flexion deformation, here and there present in non-association cases, is done at this stage. At that point the lower cut is made, subtending the ideal edge with the upper cut and meeting it at the average surface of the femoral shaft. The isolated wedge of bone is evacuated and utilized as bone join at the osteotomy site.

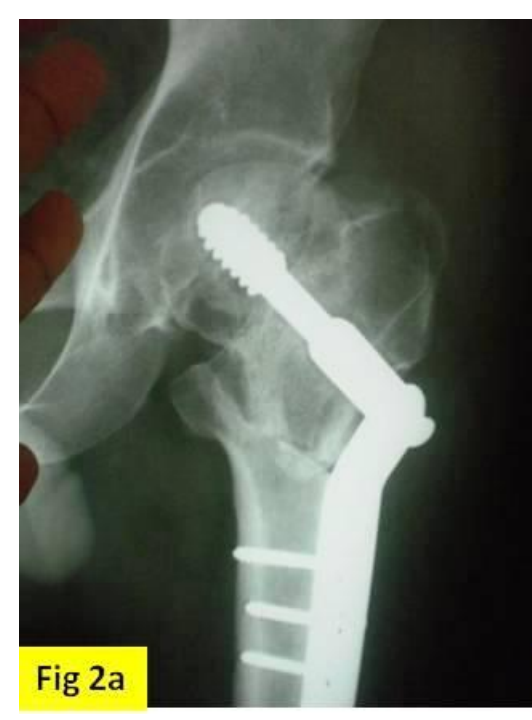

Fig $2 b$

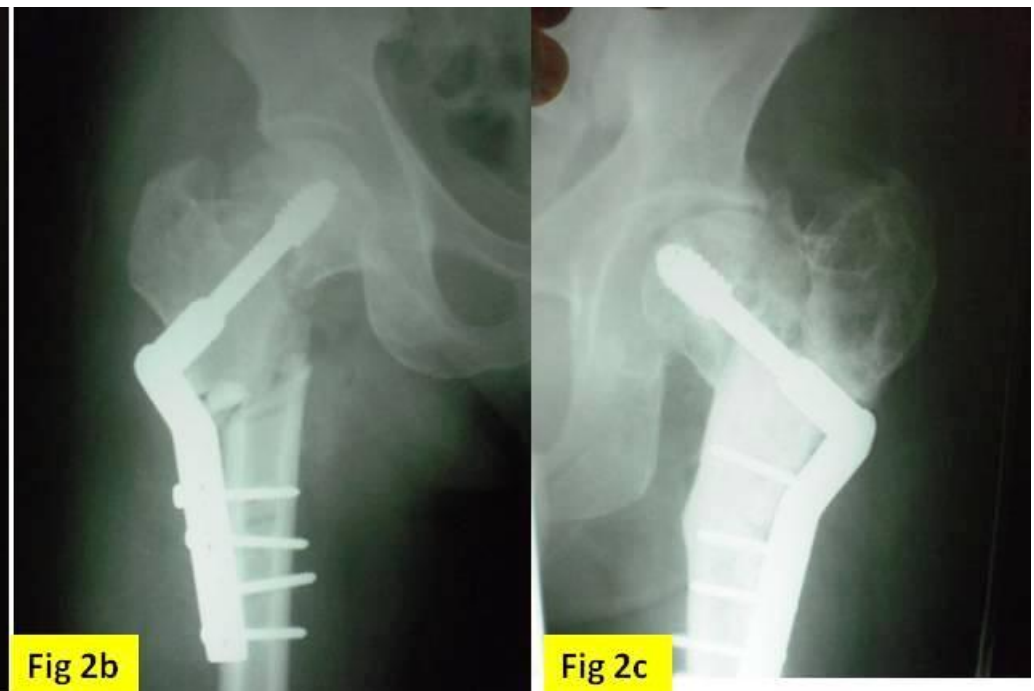

Fig 2 


\section{Osteotomy reduction}

While snatching the hip to close the osteotomy, the femoral shaft is pulled along the side and distally by a bone snare to convey it to the plate, and a clasp is connected to hold them together. The main screw along the pole is set at a slant parallel to the osteotomy cut. Fixing this screw helps pull the femoral shaft along the side and distally and pack the osteotomy surfaces. Postagent the board Hip and knee scope of movement and muscle reinforcing practices were founded for the whole furthest point. Touchdown weight bearing was allowed for the initial a month and a half after medical procedure, and afterward expanded to full weight bearing as indicated by the advancement of break and osteotomy mending seen on the radiographs. Follow-up After doctor's facility release, patients were watched occasionally at regular intervals until the point when break recuperating. Follow-up extended somewhere in the range of one and five (normal 3.5) years.

Appraisal Crack and osteotomy association was evaluated radiographically after total vanishing of the break line and the osteotomy site. Clinical association was affirmed when there was easy hip scope of development and effortless full weight bearing. Utilitarian evaluation was finished utilizing emotional and target data dependent on torment, appendage shortening and strolling capacity.

\section{Materials and Method}

This examination was done in the creators' establishment, a college showing doctor's facility, between January 2008 to December 2013. It included 14 patients: 11 men and 3 ladies. Their normal age was 37.14 (24-47) years. Two were ununited cracks after fizzled interior obsession. While rest 12 introduced late. All patients were treated by wedge-evacuating valgus between subtrochanteric osteotomy. The obsession gadget was $120^{\circ}$ twofold calculated DHS in all patients. The investigation was endorsed by the moral board of trustees of our establishment.

\section{Surgeries}

The activity is performed on a radiolucent break table under fluoroscopic direction. The guide wire is embedded going for the infero-average quadrant of the femoral head at the pre-templated inclusion edge. Its position is checked by fluoroscopy, and after that the DHS is embedded. Boring and tapping was done over the guide wire. The side plate embedded over the screw currently stands from the femoral shaft, making an edge equivalent to the ideal osteotomy edge (Fig. 2c). A V-molded wedge evacuating osteotomy is performed. The upper cut of the osteotomy is transverse. Revision of any outside revolution or flexion disfigurement, at times present in non-association cases, is done at this stage. At that point the lower cut is made, subtending the ideal edge with the upper cut and meeting it at the average surface of the femoral shaft. While stealing the hip to close the osteotomy, the femoral shaft is pulled along the side and distally by a bone snare to bring it close to the plate, and a clip is connected to hold them together and pack the osteotomy.

\section{Post-agent the executives}

Hip and knee scope of movement and muscle fortifying activities were initiated for the whole furthest point. Touchdown weight bearing was allowed for the initial a month and a half after medical procedure, and afterward expanded to full weight bearing as per the advancement of crack and osteotomy recuperating seen on the radiographs. Follow-up After clinic release, patients were watched intermittently like clockwork until the point that crack recuperating. Follow-up extended somewhere in the range of one and five (normal 3.5) years.

\section{Result}

Crack and osteotomy association was evaluated radiographically after total vanishing of the break line and the osteotomy site. Clinical association was affirmed when there was easy hip scope of development and effortless full weight bearing. Utilitarian evaluation was finished utilizing emotional and target data dependent on agony, 
appendage shortening and strolling capacity. Osteotomy structure, Careful preoperative arranging was done for each situation (Fig. 2a-c). To start with, the crack edge, between the break plane and opposite to the femoral hub, is estimated in a standard anteroposterior radiograph. Second, the osteotomy point is estimated (Fig. 2a). This point is equivalent to the crack edge short $25^{\circ}$ which is the consequence of the compressive powers at the hip [13] (Fig. 2b).
Third, the seating etch addition point is recognized, which is the edge of the cutting edge plate $\left(130^{\circ}\right)$ less the osteotomy edge. On the off chance that the osteotomy edge is $40^{\circ}$, the point between the seating etch and the femoral shaft will be $90^{\circ}$. Fourth, the section purpose of the seating etch ought to be in any event $2.5 \mathrm{~cm}$ over the arranged upper cut of the osteotomy. Osteotomy level is at or somewhat better than the lesser trochanter level.

Table 1 Details of patients with non-unions and treatment outcome

\begin{tabular}{|c|c|c|c|c|c|c|c|c|c|}
\hline \multirow[t]{2}{*}{ S1 No } & \multirow[t]{2}{*}{ Age/sex } & \multirow{2}{*}{$\begin{array}{c}\text { Duration } \\
\text { of fracture } \\
\text { (weeks) }\end{array}$} & \multirow{2}{*}{$\begin{array}{l}\text { Amount of } \\
\text { shortening }\end{array}$} & \multicolumn{2}{|c|}{$\begin{array}{l}\text { Average Harris } \\
\text { hip score }\end{array}$} & \multicolumn{2}{|c|}{ Neck Shaft angle } & \multirow[t]{2}{*}{ Out come } & \multirow{2}{*}{$\begin{array}{l}\text { Follow up } \\
\text { (Month) }\end{array}$} \\
\hline & & & & Pre & Post & Pre & Post & & \\
\hline 1 & $27 / \mathrm{M}$ & 8 & 1.6 & 78 & 12 & 95 & 125 & Fracture united & 10 \\
\hline 2 & $45 / \mathrm{M}$ & 4 & 1.2 & 80 & 15 & 90 & 130 & Fracture united & 23 \\
\hline 3 & $32 / \mathrm{M}$ & 5 & 1.5 & 79 & 16 & 100 & 130 & Fracture united & 14 \\
\hline 4 & $47 / \mathrm{F}$ & 12 & 2.0 & 72 & 11 & 105 & 135 & Fracture united & 36 \\
\hline 5 & $33 / \mathrm{M}$ & 8 & 2.1 & 82 & 11 & 98 & 130 & Fracture united & 18 \\
\hline 6 & $42 / \mathrm{F}$ & 16 & 1.6 & 76 & 10 & 108 & 140 & Fracture united & 12 \\
\hline 7 & $38 / \mathrm{M}$ & 14 & 1.8 & 69 & 13 & 95 & 135 & Fracture united & 19 \\
\hline 8 & $41 / \mathrm{F}$ & 12 & 2.3 & 74 & 12 & 100 & 130 & AVN & 17 \\
\hline 9 & $36 / \mathrm{M}$ & 16 & 2.6 & 77 & 11 & 90 & 130 & Fracture united & 18 \\
\hline 10 & $24 / \mathrm{M}$ & 11 & 1.4 & 76 & 12 & 100 & 135 & Fracture united & 20 \\
\hline 11 & $30 / \mathrm{M}$ & 10 & 2.2 & 75 & 11 & 95 & 130 & Fracture united & 23 \\
\hline 12 & $39 / \mathrm{M}$ & 8 & 1.8 & 79 & 10 & 100 & 135 & Fracture united & 26 \\
\hline 13 & $42 / \mathrm{M}$ & 9 & 2.6 & 82 & 13 & 95 & 130 & Fracture united & 24 \\
\hline 14 & $44 / \mathrm{M}$ & 10 & 1.4 & 81 & 14 & 90 & 135 & Fracture united & 26 \\
\hline
\end{tabular}

\section{Discussion}

Non-association of femoral neck breaks in the youthful has dependably been testing ${ }^{[5]}$. Arthrodesis isn't acknowledged in the individuals who work on hunching down and sitting on the floor. Add up to hip substitution in the youthful is related with numerous issues. Valgus intertrochanteric osteotomy is an elective line of treatment for those patients ${ }^{[1-3,8,11]}$. Pauwels ${ }^{[15]}$ and Müller ${ }^{[14]}$ prompted Y-molded wedgeclosing-wedge-opening osteotomy to treat pseudo-arthrosis of the femoral neck. The Ymolded osteotomy diminishes the region of contact of the osteotomy surfaces. Then again, straightforward V-molded wedge evacuating osteotomy gives wide osteotomy surfaces that guarantee great hard contact on conclusion of the osteotomy and lateralisation of the femoral shaft. Valgus intertrochanteric osteotomy results in revolution of the upper fragment of the femur in a clockwise way for the left hip and counterclockwise for the correct hip. The osteotomy line turns out to be at a slant arranged, running downwards and along the side, and its parallel end is uprooted distally, bringing about stretching (Fig. 3). Protracting is typically alluring to make up for the shortening that is available in these cases ${ }^{[10]}$. The femoral shaft is currently dislodged medially and turns out to be vertically arranged after the osteotomy. Osteotomy obsession with a twofold calculated plate will keep up this distorted position (Fig. 1). Then again, obsession with a solitary calculated sharp edge plate will pull the femoral shaft horizontally and distally to the plate along the incline of the diagonally arranged osteotomy line. This will result in remedy of the medialisation of the femoral shaft and furthermore reestablish the 
typical tendency of the femur to the sagittal plane. These impacts affect the knee joint in counteracting valgus strain and over-burdening. The compressive powers at the hip subtend a point of $25^{\circ}$ with the anatomical hub of the femur (Fig. $2 b)$. On the off chance that the break plane is leaned back to subtend this edge with the anatomical hub of the femur, it is under unadulterated pressure ${ }^{[13]}$. Valgus decrease of vertical femoral-neck cracks is a technique used to accomplish this objective. Valgus over-decrease, in any case, may result in avascular corruption of the femoral make a beeline for wrinkling and deterrent of the postero-predominant retinacular vessels. Realignment of the break at the intertrochanteric level by a valgus osteotomy and inward obsession gives protected, elective adjustment of these cracks and non-associations ${ }^{[1,3,6,9]}$. In femoral neck nonunions, repositioning the osteotomy will result in association of the pseudarthrosis, even within the sight of avascular rot. In any case, the hip capacity may weaken in these cases later on ${ }^{[14]}$. The downside of the valgus intertrochanteric osteotomy

is diminishing abductor muscle effectiveness and expanding the joint responsive power because of shortening of its switch arm as an impact of pivot and adduction of the upper portion of the femur. This is likely dependable, at any rate to a limited extent, for the diligent limp announced in $25 \%$ of our patients following the osteotomy. In this examination, we favored the settled singlecalculated cutting edge plate to the dynamic hip screw (DHS), as it abstains from reaming the femoral head and limits the danger of avascular corruption. It likewise gives great buy when embedded in the inferomedial quadrant of the femoral head, even in the osteopenic bone, without the danger of slicing through the femoral head. Besides, the settled point edge plate does not permit medialisation of the femoral shaft, as DHS may do through its skimming impact. The impediments of this investigation are the review plan what's more, absence of a control aggregate utilizing the twofold calculated osteotomy plates.
Be that as it may, the aftereffects of this investigation support the utilization of $120^{\circ}$ twofold calculated DHS plate for valgus intertrochanteric osteotomy obsession to realign vertical femoral neck cracks and non-associations in moderately youthful grown-up patients.

\section{Reference}

1. Meyers MH, Harvey JP Jr, Moore TM. Treatment of displaced subcapital and transcervical fractures of the femoral neck by muscle-pedicle-bone graft and internal fixation. A preliminary report on one hundred and fifty cases. J Bone Joint Surg Am 1973;55:257-74.

2. Mathews V, Cabanela ME. Femoral neck nonunion treatment. Clin Orthop Relat Res 2004;419:57-64.

3. Banks HH. Nonunion in fractures of the femoral neck. Orthop Clin North Am 1974;5:865-85.

4. Lifeso R, Younge D. The neglected hip fracture. J Orthop Trauma 1990;4:287-92.

5. Kalra M, Anand S. Valgus intertrochanteric osteotomy for neglected femoral neck fractures in young adults. Int Orthop 2001;25:363-6.

6. Nagi ON, Dhillon MS, Gill SS. Fibular osteosynthesis for delayed type II and type III femoral neck fractures in children. J Orthop Trauma 1992;6:306-13.

7. Hernefalk L, Messner K (1996) Rigid osteosynthesis decreases the late complication after femoral neck fracture: the influence of three different devices evaluated in 369 patients. Arch Orthop Trauma Surg 115:71-74

8. Kalra M, Anand S (2001) Valgus intertrochanteric osteotomy for neglected femoral neck fractures in young adults. Int Orthop 25:363-366

9. Magua NK, Singha R, Mittala R, Garga R, Wokhlub A, Sharmaa AK (2005) Osteosynthesis and primary valgus intertrochanteric osteotomy in displaced 
intracapsular fracture neck of femur with osteoporosis in adults. Injury 36:110-122

10. Comfort TH, Chapman MW (1998) Nonunion and malunion of the hip. In: Chapman MW, Madison M (eds) Operative orthopaedics, 1 st edn. J.B. Lippincott, Philadelphia, pp 555-56

11. Brand RA (1997) Hip osteotomies: a biomechanical consideration. J Am Acad Orthop Surg 5:282-291

12. Müller ME, Allgower M, Schneider R, Willenegger H (1979) Manual of Internal fixation: techniques recommended by $\mathrm{AO}$ Group, 2nd edn. Springer-Verlag, Berlin, pp 360-365

13. Müller ME (1984) Intertrochanteric osteotomies: indications, proper planning and technique. In: Schatzker J (ed) The intertrochanteric osteotomy. SpringerVerlag, Berlin, pp 25-66

14. Müller ME (1999) The intertrochanteric osteotomy and pseudoarthrosis of the femoral head. Clin Orthop 363:5-8

15. Pauwels F (1927) Biomechanics of normal and diseased hip. Translated by Ronald J. Furlong and Paul Maquet (1976). Springer-Verlag, Berlin 